\title{
The Role of Na/K-ATPase Signaling in Oxidative Stress Related to Aging: Implications in Obesity and Cardiovascular Disease
}

\author{
David E. Bartlett ${ }^{1,+}$, Richard B. Miller ${ }^{1,+}$, Scott Thiesfeldt ${ }^{1,+}$, Hari Vishal Lakhani ${ }^{1,+}$, \\ Joseph I. Shapiro ${ }^{1}$ and Komal Sodhi ${ }^{2, *}$ \\ 1 Department of Internal Medicine, Joan C. Edwards School of Medicine, Marshall University, \\ Huntington, WV 25701, USA; bartlett14@marshall.edu (D.E.B.); miller1088@marshall.edu (R.B.M.); \\ thiesfeldt@marshall.edu (S.T.); lakhani@marshall.edu (H.V.L.); shapiroj@marshall.edu (J.I.S.) \\ 2 Department of Surgery and Biomedical Sciences, Joan C. Edwards School of Medicine, Marshall University, \\ Huntington, WV 25755, USA \\ * Correspondence: sodhi@marshall.edu; Tel: +1-304-691-1704; Fax: +1-914-347-4956 \\ + These authors contributed equally to this work.
}

Received: 10 July 2018; Accepted: 21 July 2018; Published: 23 July 2018

check for updates

\begin{abstract}
Aging has been associated with a series of pathophysiological processes causing general decline in the overall health of the afflicted population. The cumulative line of evidence suggests an important role of oxidative stress in the development and progression of the aging process and metabolic abnormalities, exacerbating adipocyte dysfunction, cardiovascular diseases, and associated complications at the same time. In recent years, robust have established the implication of $\mathrm{Na} / \mathrm{K}$-ATPase signaling in causing oxidative stress and alterations in cellular mechanisms, in addition to its distinct pumping function. Understanding the underlying molecular mechanisms and exploring the possible sources of pro-oxidants may allow for developing therapeutic targets in these processes and formulate novel intervention strategies for patients susceptible to aging and associated complications, such as obesity and cardiovascular disease. The attenuation of oxidative stress with targeted treatment options can improve patient outcomes and significantly reduce economic burden.
\end{abstract}

Keywords: aging; obesity; cardiovascular disease; oxidative stress; Na/K-ATPase signaling

\section{Introduction}

Aging is an incidental and irreversible process that is often augmented by alterations in the cellular mechanisms including, but not limited to, irrevocable DNA damage, impaired nuclear activity, compromised cell division, apoptotic processes, and oxidative stress [1-5]. This process is often characterized by phenotypic changes and an overall decline in physiological processes that further contributes to age-related complications. Numerous studies have demonstrated, yet not fully established, that aging has a causal relationship with metabolic derangements such as obesity and augment the risk of cardiovascular diseases, including atherosclerosis, hypertension, and myocardial infarction, due to increased hypertrophy, fibrosis, and an elevated number of apoptotic and necrotic cells. This association has been summarized in Figure 1. 


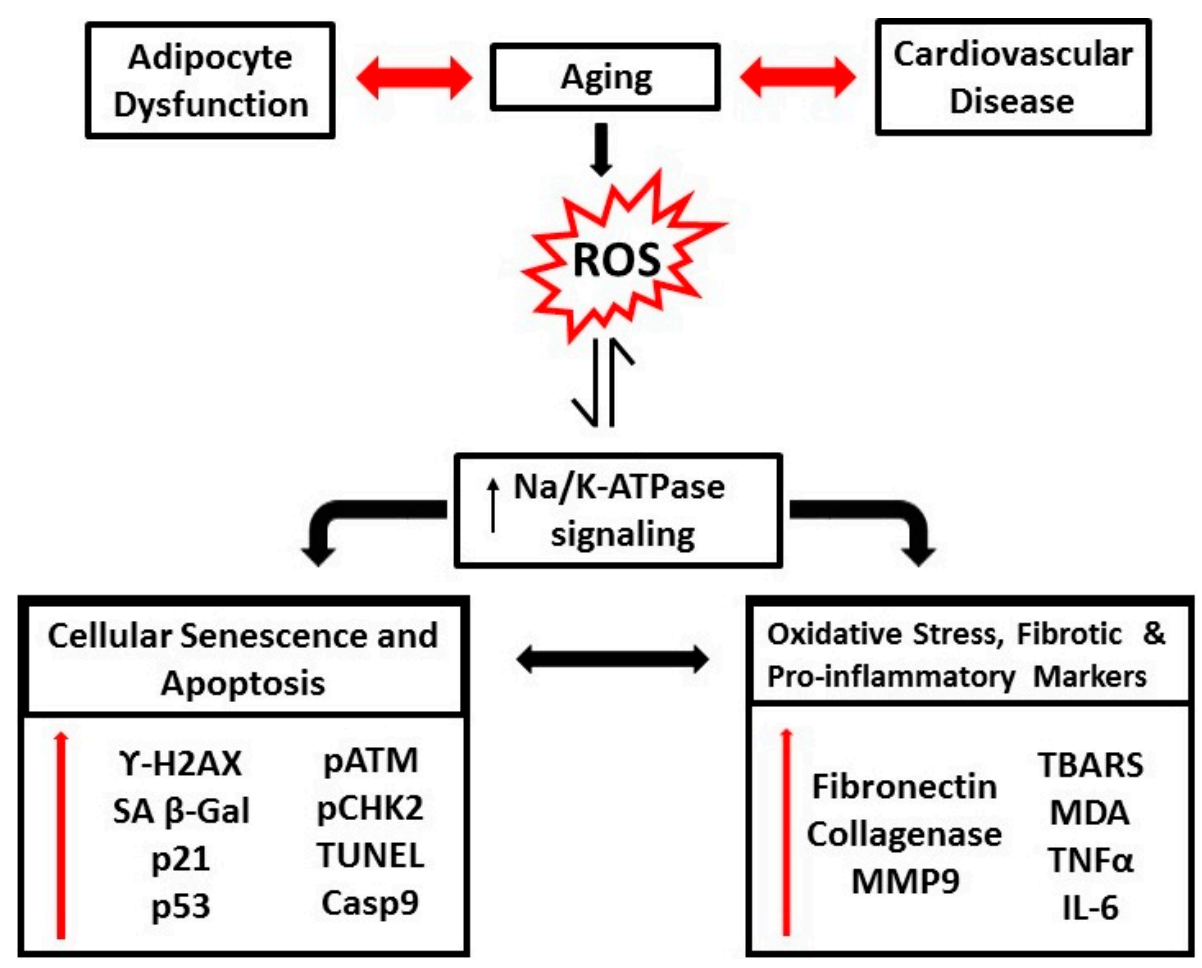

Figure 1. Schematic representation of the pathophysiological alterations in the biological aging process, in association with obesity and cardiovascular disease.

The trigger for the age-associated complications, such as obesity and cardiovascular diseases, is intricately linked with an increase in reactive oxygen species (ROS) and subsequent oxidative stress $[6,7]$. The primary sources of endogenous intracellular ROS include cellular mitochondria, endoplasmic reticulum (ER) stress, activation of the Ras pathway, and upregulated activity of NADPH oxidase (NOX) [8]. Evidence suggests that ROS-induced oxidative stress is critical in aging, exacerbating cellular injury and DNA damage, resulting in senescence and apoptosis [8,9]. Oxidative stress in aging accentuates cardiac fibrosis and inflammation, further leading to overexpression of chemokines and pro-inflammatory cytokines, giving rise to cardiovascular complications and disorders [10].

While there are multiple sources of ROS in aging and associated cardiovascular disorders, recent studies have established a mechanistic role of sodium potassium adenosine triphosphatase (Na/K-ATPase) signaling cascade in the exacerbation of oxidative stress [11-13]. Xie and his group discovered the scaffolding and signaling function of $\mathrm{Na} / \mathrm{K}$-ATPase, apart from its pumping function, over two decades ago. Since then, our group has demonstrated multiple lines of evidence suggesting the involvement of $\mathrm{Na} / \mathrm{K}-\mathrm{ATPa} e$ signaling in various disease models ranging from obesity to cancer, including our recently published data in aging models [14-16]. These studies target Na/K-ATPase signaling cascade with the goal of developing therapeutic options for the clinical disorders, which are all associated to systemic and cellular redox imbalance $[12,17,18]$. Thus, understanding the role of $\mathrm{Na} / \mathrm{K}$-ATPase signaling in oxidative stress related pathophysiology of aging and subsequent cardiovascular disease is important.

\section{Na/K-ATPase Signaling and Oxidative Stress}

The Na/K-ATPase, a P-type ATPase, has recently been shown by Xie/Shapiro laboratories to cause oxidative stress through mechanisms distinct from its well-understood pumping function (Figure 2) [19-21]. The major thrust of the Xie/Shapiro laboratories over the past twenty years has been the elucidation of a signaling function for the $\mathrm{Na} / \mathrm{K}$-ATPase that is based on the scaffolding properties of the $\alpha 1$ subunit. The $\mathrm{Na} / \mathrm{K}$-ATPase $\alpha$ - 1 subunit causes structural modulation leading to 
the activation of membrane bound Src kinase $[13,21]$. The carbonylation of $\alpha-1$ subunit is induced by excessive systemic ROS, which is greatly produced in a diseased condition, leading to the formation of $\alpha-1 /$ Src complex, resulting in phosphorylation and activation of Src $[13,22]$. The activation of Src kinase further leads to the downstream activation of signaling cascade including Ras-Raf-MEK-ERK pathway resulting in the production of excessive mitochondrial ROS. Hence, it has been evidently demonstrated that the production of ROS is not just a consequence of $\mathrm{Na} / \mathrm{K}$-ATPase signaling activation, but also plays a role in its initiation, therefore creating a $\mathrm{Na} / \mathrm{K}-\mathrm{ATPase}$ oxidant amplification loop [23,24]. Evidence suggests that the activation of Src also regulates NADPH oxidase-derived superoxide generation [25]. Protein carbonylation has also been well established as a marker for the modulation of the $\mathrm{Na} / \mathrm{K}$-ATPase signaling function under oxidative stress. It has also been demonstrated that cardiotonic steroids (CTS) and glucose-oxidase-induced $\mathrm{H}_{2} \mathrm{O}_{2}$ trigger the direct carbonylation of the $\alpha-1$ subunit, which promotes a feed forward mechanism of Na/K-ATPase signal transduction [22]. Since oxidative stress plays a key role in the progression of aging process and neurodegenerative diseases, it is imperative to examine potential targets that can restore redox imbalance.

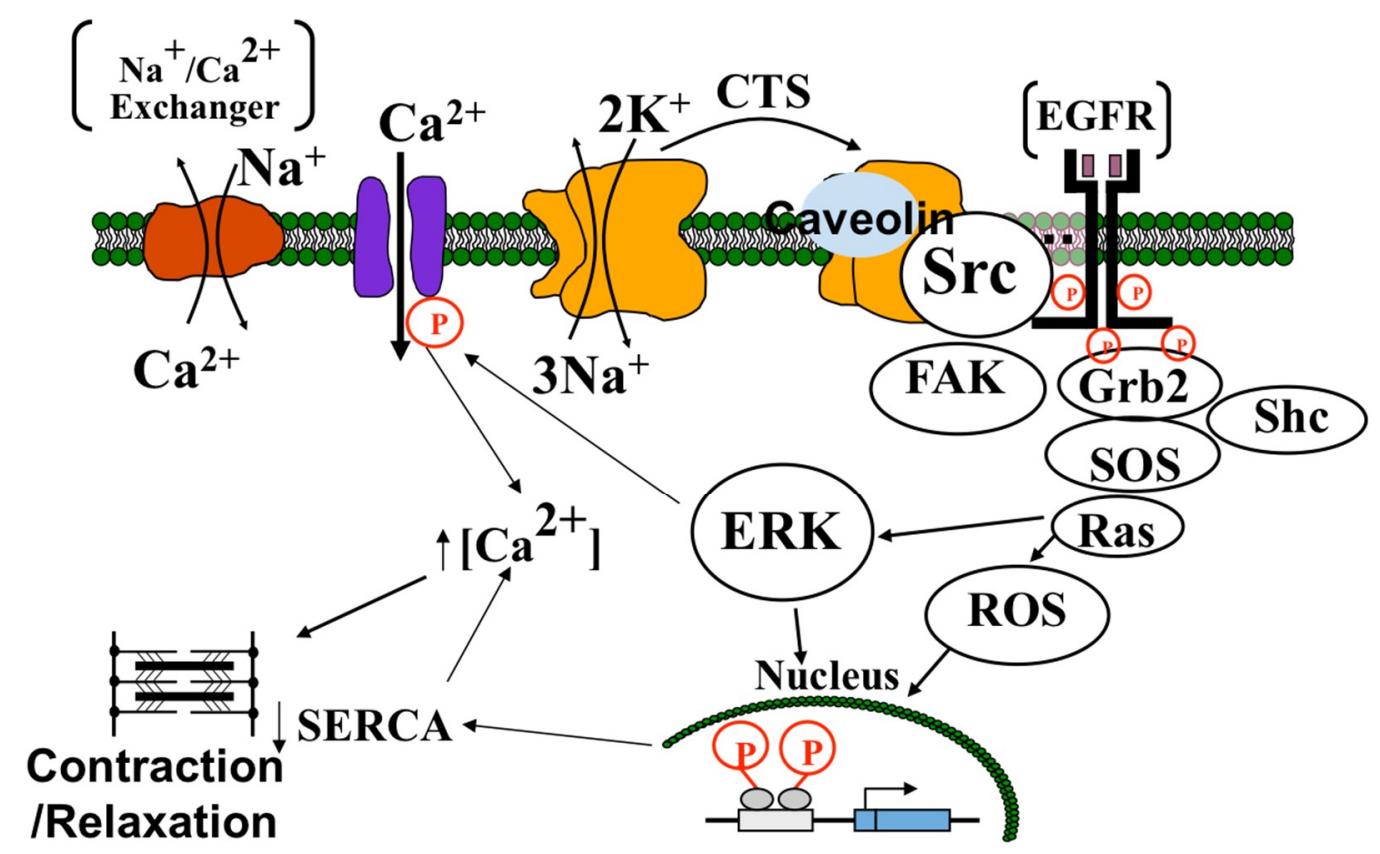

Kennedy et. al, Hypertension, 2006

Figure 2. Xie model for $\mathrm{Na} / \mathrm{K}$-ATPase signaling showing $\mathrm{Na}$ /K-ATPase (orange proteins) serving as scaffolding protein in caveolae regulating the tyrosine kinase activity of Src. Na/K-ATPase can act as a specific receptor for CTS and as a non-specific receptor for ROS. As this signal cascade generates ROS, the Na/K-ATPase-Src cascade can serve as a feed forward amplifier for ROS. Source: Kennedy et al. (2006) [26].

\section{The Development of pNaKtide}

In concordance to the previous observations and the critical role of $\mathrm{Na} / \mathrm{K}$-ATPase signaling in clinical disorders, Xie's group developed a peptide, pNaKtide that specifically acts as an antagonist of the scaffolding function of $\mathrm{Na} / \mathrm{K}$-ATPase signaling. The specific details for the development of pNaKtide have been outlined in 2009 [27]. Briefly, the portion of the $\alpha-1$ subunit that interacts with the Src kinase domain was used in this sequence to develop an effective peptide, which will allow for the inhibition of Src kinase. This peptide was further merged with the HIV-Tat (TAT) leader sequence to facilitate cellular permeation (Figure 3). The exclusivity of this peptide was noted by 
demonstrating its localization to the membrane component of the cell that essentially impede its inhibition to membrane associated Src. Consistently, this peptide, pNaKtide, hindered the formation of the $\mathrm{Na} / \mathrm{K}$-ATPase-Src complex, hence inhibiting the activation of further downstream signaling cascade. Interestingly, pNaKtide did not alter the highly regulated Src activity and did not impair the unique ionic pumping function of $\mathrm{Na} / \mathrm{K}-\mathrm{ATPa} e$.

A

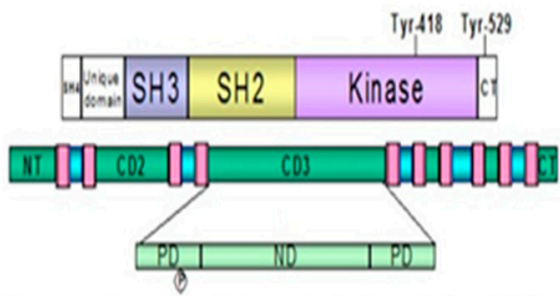

Li et. al, Journal of Biological Chemistry, 2009

B

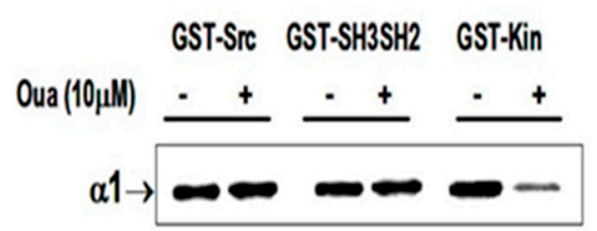

Tian et. al, Molecular Biology of the Cell, 2006
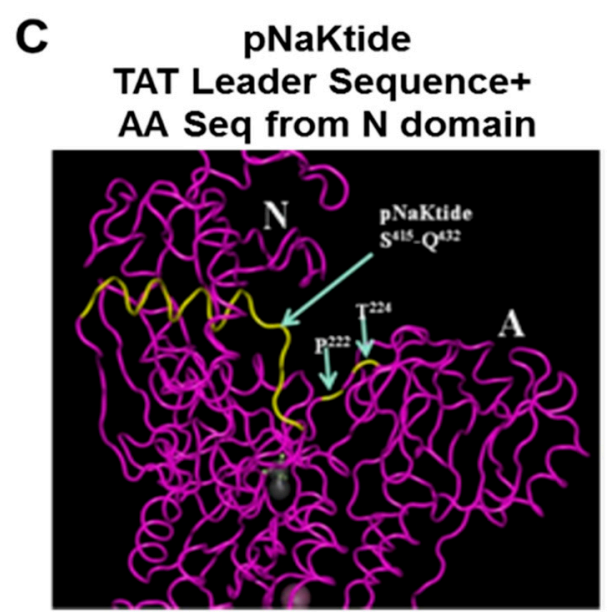

Figure 3. Depiction of alignment of the $\mathrm{Na}$ /K-ATPase alpha1 subunit with the Src Kinase domain. Further exploration defined a 20-aminoacid sequence in the $\mathrm{N}$ domain (part of CD3 domain) of alpha1, which binds Src's kinase domain (NaKtide). (A) Schematic illustration of the structure of Src representing the SH3-SH2 domain, tyrosine kinase, and different GST-fusion proteins [27]. (B) Western blot analysis demonstrating the ouabain-induced release of kinase domain from the $\mathrm{Na} / \mathrm{K}$-ATPase, blotted against anti- $\alpha-1$ antibody [28]. (C) Schematic structural representation of a portion of the TAT protein to form a 33 AA cell permeant peptide, pNaKtide. Source: Tian et al. (2006) and Li et al. (2009) $[27,28]$.

Multiple studies have demonstrated the effectiveness of $\mathrm{pNaKtide}$ and compared it with similar Src inhibitors, such as PP2. However, unlike other Src inhibitors, pNaKtide offers specificity to the $\mathrm{Na} / \mathrm{K}$-ATPase complex and evidently blocks the formation of the $\mathrm{Na} / \mathrm{K}$-ATPase/Src receptor complex, while inhibiting ouabain-induced activation of ERK1/2 and hypertrophic growth in cardiac myocytes [27]. Hence, pNaKtide functions in a specific manner and has been found to reduce oxidative stress and inhibit ROS-induced Src activation in cell preparations as well as in animal models of disease. Antioxidants alone have thus far failed in pre-clinical and clinical trials, which could be related to the lack of "range" related to specific therapy; once the scavengers are consumed, the underlying process continues as before. This peptide has been demonstrated to effectively attenuate the disease progression in the in vitro and in vivo models of studies by mediating the blockage of the $\mathrm{Na} / \mathrm{K}$-ATPase/ROS amplification loop, conclusively providing a strong evidence of its therapeutic efficacy, as well as furthering our understanding concerning the basic, cellular mechanisms operant in several clinical disorders and aging.

The cellular generation of ROS has been demonstrated to be attenuated by the administration of pNaKtide. In vitro and in vivo studies have provided significant evidence suggesting a strong potency of $\mathrm{pNaKtide}$ in ameliorating multiple clinical disorders including, but not limited to, experimental uremic cardiomyopathy, steatohepatitis, and atherosclerosis [12,18]. The recent studies effectively characterize the therapeutic potential of pNaKtide, by antagonizing Na/K-ATPase-mediated amplification of ROS signaling, subsequently preventing or reversing the diseased phenotype and restoring metabolic homeostasis in a dose-dependent manner, in murine models [11]. The ongoing research and future studies, on the effectiveness of pNaKtide, will potentially bridge the gap between 
the rodents and the humans by demonstrating its safe administration, further allowing the clinical use of pNaKtide and possibly reversing the clinical disorders.

\section{The Role of Oxidative Stress and Na/K-ATPase/ROS Signaling in Aging}

Aging is a complex, multifactorial process by which an organism, at the genetic, cellular, and organ-system level deteriorates. At the molecular level, aging has been associated with an increase in DNA mutations, telomere shortening, and changes in methylation patterns, each of which can disturb the normal expression and/or function of proteins involved in cell growth, genomic integrity, cellular stress responses, and inflammation [29,30]. Reflecting on U.S. Census population statistics and predictions, people aged 65 and older represented $15 \%$ of the total U.S. population in 2016. The future projections for the aging population suggest a rise to $22 \%$ of the population by 2050 . In addition, the aged population over 85 years contributed towards $2 \%$ of the total U.S. population in 2016 with an expected rise to $5 \%$ by 2050 . Given these trends, it is imperative to understand the molecular mechanisms critical to aging process and its associated complications.

Though the underlying mechanisms of aging remain poorly understood, a growing body of evidence points towards ROS as the causative agents of DNA, lipid, and protein damage that are associated with impairment at the cellular and tissue level [31-34]. When ROS accumulation exceeds the detoxifying ability of the cell, the resulting oxidative stress can induce damage, such as increased DNA mutations and destabilization of electron transport chain complexes, and can cause senescence or eventual apoptosis [35-37]. Given the complexity of the aging process, one of the most widely known concept is the "free radical theory of aging," which was initially coined in 1956 [38,39]. This theory extensively explains the critical role of ROS as a major determinant of lifespan while driving multiple aging processes [8]. This theory further elaborates the role mitochondrial processes in the generation of ROS, causing mtDNA point mutations, damage to cellular macromolecules, and alterations in the NADPH equilibrium. Intracellular ROS has been evidently reported to be directly and indirectly involved in the telomere shortening, which is a major cause of replicative senescence and a common process of aging. This is often associated with the significant reduction of superoxide dismutase (SOD) and the loss of ROS scavengers such as N-acetyl cysteine (NAC), which inhibits the ability of the cell to delay the onset of cellular senescence [40]. Cell senescence is largely induced and maintained through the p53 pathway [29,41,42]. In the p53 pathway, the effects of oxidative stress, such as double-strand breaks in DNA, trigger activation of ATM and CHK2, which activates p53 [29,35,43,44]. Activated p53 upregulates p21, which in turn inhibits CDK2 from phosphorylating Rb and arrests cells at the $\mathrm{G}_{1} / \mathrm{S}$ checkpoint [35,43-45]. Collectively, mitochondrial dysfunction and damage, cellular senescence, apoptosis, and altered cellular homeostasis activates the inflammatory pathways, engaging the immune system into a pro-inflammatory state, upregulating associated chemokines and cytokines, including, but not limited to, thromboxane A2, IL-1 $\beta$, TNF- $\alpha$, and IL-6 [46,47]. Such age-related systemic inflammation has been termed as "inflammaging," exacerbating the aging process [48]. Understanding the interactions between these factors and redox imbalance is vital in providing a deeper insight in the aging process and associated complications.

Since oxidative stress plays a key role in the process of aging, our group examined a potential therapeutic target that can restore the oxidant equilibrium. We demonstrated the role of the $\mathrm{Na} / \mathrm{K}$-ATPase oxidant amplification loop in the exacerbation of oxidant injury in aging, while the peptide, pNaKtide, negated the activation of the $\mathrm{Na} / \mathrm{K}$-ATPase signaling cascade. We established an in vivo model of aging, using 2-month-old and 16-month-old C57BL/ 6 mice. The results showed an increase in body weight, visceral fat, and subcutaneous fat in old mice, while consistent with these observations, the locomotor activity and the overall energy expenditure was shown to be decreased, as compared to the young mice. These differences were negated by the administration of pNaKtide in old mice, suggesting a strong efficacy of this peptide. Because senescence is a hallmark of aging, we investigated if modulating $\mathrm{Na} / \mathrm{K}$-ATPase signaling affected oxidation-induced cell senescence in vitro. We performed in vitro studies in human dermal fibroblasts (HDFs), inducing senescent 
phenotype by treatment with $\mathrm{H}_{2} \mathrm{O}_{2}$, ouabain (CTS), ultraviolet radiation, and glucose oxidase (GO). We demonstrated the overexpression of oxidation-induced senescent and apoptotic markers, including p21, p53, pATM, pCHK2, ApoJ, fibronectin, MMP9, collagenase, $\gamma$-H2AX, and SA $\beta$-Gal, which was ameliorated by the $\mathrm{Na} / \mathrm{K}-\mathrm{ATP}$ ase signaling antagonist, pNaKtide. In addition to senescence, cell injury and apoptosis are all markers of oxidative stress [49]. Evidence suggests that, during the aging process, there is a significant release of $\mathrm{H}_{2} \mathrm{O}_{2}$ by mitochondria that aids in inducing oxidative stress. In our study, $\mathrm{H}_{2} \mathrm{O}_{2}$ and ouabain exposure increased levels of cell injury and apoptotic markers. Subsequent pNaKtide treatment decreased these factors, supporting the hypothesis that $\mathrm{Na} / \mathrm{K}$-ATPase signaling affects the overall oxidation levels in cells. To ensure that the above effects were the result of $\mathrm{Na} / \mathrm{K}-\mathrm{ATP}$ ase signaling, we looked at markers of signaling activation: protein carbonylation and phosphorylation of Src. Previous studies have shown that $\alpha 1$ carbonylation is a critical mediator of $\mathrm{Na} / \mathrm{K}$-ATPase signaling under oxidative stress conditions. Consistent with previous studies, protein carbonylation and Src phosphorylation increased in our in vitro and in vivo aging models and decreased following pNaKtide treatment. Taken together, these data indicate that inhibition of $\mathrm{Na} / \mathrm{K}$-ATPase signaling was able to reverse oxidation-induced senescence and apoptosis at both the morphological and molecular level [16].

\section{The Role of Oxidative Stress and Na/K-ATPase/ROS Signaling in Aging and Associated Obesity}

Obesity is regarded as an excess accumulation of adipose tissue, resulting in a body mass index (BMI) greater than 30. Obesity and aging has been implicated in multiple studies, suggesting the aggravation of the biological aging process. The prevalence of obesity in the population aged 60 years and older was 41.0\% in the United States between 2015 and 2016 [50]. The risk ratio of all-cause mortality for people who were obese and were 50 years of age and older was 1.25 , highlighting the importance for investigating the underlying mechanisms which contribute to both age and obesity [51]. This could potentially alleviate many burdens imposed on both patients and the healthcare system.

Oxidative stress is a key inducer of obesity through induction of adipogenesis and dysregulation of adipocyte phenotype [52]. This oxidative-stress-induced phenotypic alteration increases adipogenic markers such as peroxisome proliferation factor- $\gamma$ (PPAR- $\gamma$ ) [53], fatty acid synthase (Fas) [54], and mesoderm-specific transcript protein (Mest) [55], along with pro-inflammatory cytokines including TNF- $\alpha$ and IL-6, which exacerbates the aging process [56], causing senescence and DNA damage. The production of ROS characterized in obesity and aging, which leads to oxidative stress, can be partly attributed to mitochondrial dysfunction, which is further exacerbated by decreased levels of antioxidants [57,58]. The interplay between obesity and oxidative stress in adipose tissue modifies the secretome toward a pro-inflammatory composition of adipokines $[59,60]$. This altered secretome generates low grade (chronic) inflammation, which exacerbates adipocyte dysfunction and impairs the metabolic profile to increase levels of lipids, free fatty acids (FFAs), glucose, and ROS when aging and obesity coexist [61]. This process creates a vicious cycle of ROS production and the release of pro-inflammatory cytokines in obesity and aging [59]. Oxidative stress and low grade (chronic) inflammation observed in obesity accelerates the shortening of telomeres by damaging G-rich sequences, which is further intensified by a reduced capacity of DNA repair in these sequences, suggesting a hastened aging process [62]. To further strengthen the evidence that obesity exacerbates aging, various studies in humans have demonstrated an inverse correlation between telomere length and abdominal adiposity [63], as well as p53 protein pathway, a key regulatory pathway in aging, playing a vital role in adipose tissue associated with obesity [64]. Aging and obesity synergistically lead to the accumulation of senescent cells along with senescence-associated secretory phenotype (SASP) generating further increased DNA damage and oxidative stress [65]. Aging and obesity reduce longevity by deleterious effects on the structure and function of organs due to oxidative stress, genetic instability, and disturbances of homeostatic pathways [66]. The demonstration that the Na/K-ATPase oxidant amplification loop plays a key role in the generation and amplification of ROS highlights the 
importance of investigating its role in diseases such as obesity that are intimately linked to high levels of oxidative stress $[13,22]$. The Na/K-ATPase oxidant amplification loop has been shown to induce adipocyte dysfunction in murine preadipocyte (3T3-L1) cell lines, and pNaKtide attenuated not only the oxidant stress but also adipogenesis [11]. A recent study showed that 16-month-old C57BL/ 6 mice fed a high fat diet significantly increased body weight, visceral fat, and subcutaneous fat, as compared to young and old mice fed a normal chow diet. These levels were attenuated after the administration of pNaKtide [16]. This exemplifies the importance of utilizing $\mathrm{Na} / \mathrm{K}$-ATPase signaling as a therapeutic target in an effort to ameliorate aging and obesity.

\section{The Role of Oxidative Stress and Na/K-ATPase/ROS Signaling in Aging and Associated Cardiovascular Diseases (CVDs)}

Age is a major risk factor for cardiovascular diseases (CVDs), not only because it prolongs exposure to several other cardiovascular risks but also because of its intrinsic cardiac aging. Intrinsic cardiac aging is defined as the slowly progressive age-dependent degeneration and decline in function, which makes the heart more vulnerable to stress and contributes to increased cardiovascular morbidity and mortality in the elderly. Almost 85.6 million American adults are projected to have one or more type of CVD, while 43.7 million of them are estimated to be greater than or equal to 60 years old [67]. Approximately two-thirds of CVD mortality occurs in people 75 years of age or older, making it a principle cause of death globally. The socioeconomic burden for CVD patients 65 years and older was estimated to be $\$ 116.9$ billion [67]. The mechanisms operant in this frightening clinical phenotype is unclear but appears to involve the constellation of severe diastolic dysfunction, left ventricular hypertrophy, and systemic oxidant stress [17,68]. A number of investigators have proposed that oxidant stress is both a feature of this clinical syndrome as well as a pathophysiological contributor or cause [69-71].

Oxidative stress plays a central role in the biological aging process, resulting in the decline of cellular defensive mechanisms that scavenges ROS. The cardiovascular system in the aging process is more prone to damage by the excessive intracellular ROS due to the presence of a significantly higher mitochondrial activity, which is a main source of ROS generation, in the myocardium. A substantial line of evidence suggests that excessive ROS in the myocardium can cause myocardium senescence, consequently leading to apoptosis, endoplasmic reticulum (ER) stress, lipofuscin formation, and activation of pro-inflammatory pathways $[7,38,72]$. Age-induced oxidative stress is paramount in contributing towards cardiovascular and cardiac structural damage. With aging, the endothelial cells and vascular smooth muscle cells produce ROS, which interacts with nitrogen species, further oxidizing the low-density lipoproteins (LDL) that migrate to cardiac vasculature, exacerbating atherosclerosis. Numerous studies have also demonstrated a strong correlation between the age-related excess ROS generation and an inclined cardiac myocyte death [38]. The various well-studied sources of ROS generation in CVD includes impaired NADPH oxidase (NOX) activity, mitochondrial dysfunction, xanthine oxidase, and uncoupled nitric oxide synthases [73]. Consistent with the noted increase in the endogenous ROS production, there is significant reduction of greater than $50 \%$ in antioxidant enzyme activity, including manganese superoxide dismutase (MnSOD), catalase (CAT), glutathione peroxidase (GPx), and glutathione S-transferase (GST), as noted in the cardiovascular system of rodents [74]. Additionally, cardiac aging in the murine model demonstrated a significantly greater lipid peroxidation in the aged heart when compared to the heart tissues from young mice [74]. Such decline in heart function due to the age-related oxidative stress often leads to a significant reduction in cardiac output and heart rate, which encapsulates structural changes such as fibrosis [7].

Cardiac aging in the murine model closely recapitulates the age-related cardiac changes, which has been demonstrated by our recent study that establishes a basis for the role of the $\mathrm{Na} / \mathrm{K}$-ATPase oxidant amplification loop in exacerbating the cardiac damage. Transthoracic Echocardiography performed on an in vivo aging model demonstrated that there were significant age-dependent linear trends in increased left-ventricular mass index (LVMI), posterior wall thickness (PWT) and relative wall thickness (RWT), in the oldest group compared to young controls. The myocardial performance index significantly 
worsened with age and indicates that a greater fraction of systole is spent to cope with the pressure changes during isovolumic phases. However, administration of pNaKtide attenuated these impairments and improved cardiac function. Further evidence demonstrated a significant increase in senescence and apoptotic markers, including ApoJ, fibronectin, and p21, in the heart tissue of C57BL/6 aging mice, which was negated by pNaKtide. The determination of magnitude of cardiac fibrosis, in the heart tissue of aging mice, was shown to be excessive with a clear demonstration of fragmented degraded myofibers. However, the $\mathrm{Na} / \mathrm{K}$-ATPase antagonism through pNaKtide attenuated this cardiac damage. Protein carbonylation and Src phosphorylation, in vivo, suggests the importance of the Na/K-ATPase oxidant amplification loop in aggravating the detrimental cardiovascular damage in aging [16].

\section{Pharmacological Interventions for Aging}

Extensive research on the manifestation of biological aging process has presented with various pharmacological interventions that can improve longevity and battle the underlying mechanisms operant in age-associated cellular senescence and apoptosis. One of the intervention strategy involves the modulation of senescent associated secretory phenotype (SASP) regulatory pathways that acts by the interference with paracrine signaling of the senescent cells. The key factor involved in the SASP regulation includes the stimulation of the NF- $\mathrm{kB}$ pathway $[75,76]$, the mammalian target of rapamycin (mTOR) pathway [77,78], the mitogen activated protein kinase (MAPK) [79], and the activation of pro-inflammatory pathways. Another important marker associated with SASP regulation is transcription growth factor- $\beta$ (TGF $\beta$ ), which has the potential to induce senescence via the autocrine and paracrine signaling, allowing for the release of excessive ROS in the system, triggering DNA damage and causing cell cycle arrest $[80,81]$. In concordance to the activation of these pathways, some commercially available therapeutic interventions include Rapamycin, which inhibits the mTOR pathway, Resveratrol and Metformin, which inhibit the NF-kB pathway, and Cortisol/Corticosterone, which is a group of steroid hormones inhibiting the release of pro-inflammatory cytokines $[82,83]$. Some anti-aging therapies involve the selective elimination of senescent cells by the modulation of pathways that contribute to apoptosis, including the PI3K and Bcl-2 pathways. These pathways are impeded by the use of recently classified senolytic drugs, including quercetin, dasatinib, and navitoclax $[82,84,85]$.

Although these drugs have demonstrated a great pharmacological impact on aging, studies have shown less selectivity of these drugs, towards underlying pathways [82]. Based on these observations, our peptide, pNaKtide, has shown specific antagonism to the $\mathrm{Na}$ /K-ATPase signaling pathway, which plays a critical role in the amplification of oxidative stress in several clinical disorders including aging. We have established the critical role of the $\mathrm{Na} / \mathrm{K}$-ATPase oxidant amplification loop, which has allowed for the exploration of developing a new pharmaceutical approach to improving longevity and diseased physiology.

\section{Conclusions}

This review aims to highlight the significance of the Na/K-ATPase oxidant amplification loop in the process of aging as well as associated obesity and cardiovascular disease. We demonstrate that the aging process propagates cellular oxidative stress, senescence, and apoptosis, activating inflammatory pathways and cellular signaling pathways, such as $\mathrm{Na} / \mathrm{K}$-ATPase, which exacerbates the pathophysiological condition. Aging-induced oxidative stress also leads to alterations of adipocyte phenotype and dysfunction in an obese state, while causing cardiac vasculature damage and fibrosis, further amplifying cardiovascular diseases. The recently established role of activated Na/K-ATPase signaling in the production of excessive ROS contributes to the pro-oxidant state of cells, affecting cellular mechanisms. Further investigating the role of $\mathrm{Na} / \mathrm{K}$-ATPase signaling in perpetuating aging could provide potential therapeutic target for developing anti-aging intervention strategies. In this regard, the peptide, pNaKtide, has demonstrated profound effects as an antagonist of $\mathrm{Na} / \mathrm{K}$-ATPase signaling, contributing towards the inhibition of oxidant amplification loop and preventing disease progression. We provide a basis for new implications of $\mathrm{Na} / \mathrm{K}$-ATPase signaling in attenuating clinical 
disorders and suggest broader applications of this signaling cascade in reversing or preventing the development and progression of oxidative stress related pathologies.

Funding: This work was supported by the National Institutes of Health Grants to J.I.S. (HL109015, HL105649, and HL071556), and by the Brickstreet Foundation (J.I.S.). Its contents are solely the responsibility of the authors and do not necessarily represent the official views of the National Institutes of Health.

Conflicts of Interest: The authors declare no conflict of interest.

\section{References}

1. Davidovic, M. Genetic stability: The key to longevity? Med. Hypotheses 1999, 53, 329-332. [CrossRef] [PubMed]

2. Risques, R.A.; Lai, L.A.; Brentnall, T.A.; Li, L.; Feng, Z.; Gallaher, J.; Mandelson, M.T.; Potter, J.D.; Bronner, M.P.; Rabinovitch, P.S. Ulcerative colitis is a disease of accelerated colon aging: Evidence from telomere attrition and DNA damage. Gastroenterology 2008, 135, 410-418. [CrossRef] [PubMed]

3. Fraga, M.F.; Ballestar, E.; Paz, M.F.; Ropero, S.; Setien, F.; Ballestar, M.L.; Heine-Suner, D.; Cigudosa, J.C.; Urioste, M.; Benitez, J.; et al. Epigenetic differences arise during the lifetime of monozygotic twins. Proc. Natl. Acad. Sci. USA 2005, 102, 10604-10609. [CrossRef] [PubMed]

4. Baylin, S.B.; Herman, J.G.; Graff, J.R.; Vertino, P.M.; Issa, J.P. Alterations in DNA methylation: A fundamental aspect of neoplasia. Adv. Cancer Res. 1998, 72, 141-196. [PubMed]

5. Hanahan, D.; Weinberg, R.A. The hallmarks of cancer. Cell 2000, 100, 57-70. [CrossRef]

6. Abdollahi, M.; Moridani, M.Y.; Aruoma, O.I.; Mostafalou, S. Oxidative stress in aging. Oxidative Med. Cell. Longev. 2014, 2014, 876834. [CrossRef] [PubMed]

7. North, B.J.; Sinclair, D.A. The intersection between aging and cardiovascular disease. Circ. Res. 2012, 110, 1097-1108. [CrossRef] [PubMed]

8. Cui, H.; Kong, Y.; Zhang, H. Oxidative stress, mitochondrial dysfunction, and aging. J. Signal Transduct. 2012, 2012, 646354. [CrossRef] [PubMed]

9. Chandrasekaran, A.; Idelchik, M.; Melendez, J.A. Redox control of senescence and age-related disease. Redox Biol. 2017, 11, 91-102. [CrossRef] [PubMed]

10. Sallam, N.; Laher, I. Exercise modulates oxidative stress and inflammation in aging and cardiovascular diseases. Oxidative Med. Cell. Longev. 2016, 2016, 7239639. [CrossRef] [PubMed]

11. Sodhi, K.; Maxwell, K.; Yan, Y.; Liu, J.; Chaudhry, M.A.; Getty, M.; Xie, Z.; Abraham, N.G.; Shapiro, J.I. Pnaktide inhibits $\mathrm{Na} / \mathrm{K}$-ATPase reactive oxygen species amplification and attenuates adipogenesis. Sci. Adv. 2015, 1, e1500781. [CrossRef] [PubMed]

12. Liu, J.; Tian, J.; Chaudhry, M.; Maxwell, K.; Yan, Y.; Wang, X.; Shah, P.T.; Khawaja, A.A.; Martin, R.; Robinette, T.J.; et al. Attenuation of $\mathrm{Na} / \mathrm{K}$-ATPase mediated oxidant amplification with pnaktide ameliorates experimental uremic cardiomyopathy. Sci. Rep. 2016, 6, 34592. [CrossRef] [PubMed]

13. Wang, Y.; Ye, Q.; Liu, C.; Xie, J.X.; Yan, Y.; Lai, F.; Duan, Q.; Li, X.; Tian, J.; Xie, Z. Involvement of Na/K-ATPase in hydrogen peroxide-induced activation of the Src/ERK pathway in LLC-PK1 cells. Free Radic. Biol. Med. 2014, 71, 415-426. [CrossRef] [PubMed]

14. Yan, Y.; Shapiro, J.I. The physiological and clinical importance of sodium potassium atpase in cardiovascular diseases. Curr. Opin. Pharmacol. 2016, 27, 43-49. [CrossRef] [PubMed]

15. Li, Z.; Zhang, Z.; Xie, J.X.; Li, X.; Tian, J.; Cai, T.; Cui, H.; Ding, H.; Shapiro, J.I.; Xie, Z. Na/K-ATPase mimetic pnaktide peptide inhibits the growth of human cancer cells. J. Biol. Chem. 2011, 286, 32394-32403. [CrossRef] [PubMed]

16. Sodhi, K.; Nichols, A.; Mallick, A.; Klug, R.L.; Liu, J.; Wang, X.; Srikanthan, K.; Goguet-Rubio, P.; Nawab, A.; Pratt, R.; et al. The Na/K-ATPase oxidant amplification loop regulates aging. Sci. Rep. 2018, 8, 9721. [CrossRef] [PubMed]

17. Srikanthan, K.; Shapiro, J.I.; Sodhi, K. The role of Na/K-ATPase signaling in oxidative stress related to obesity and cardiovascular disease. Molecules 2016, 21, 1172. [CrossRef] [PubMed] 
18. Sodhi, K.; Srikanthan, K.; Goguet-Rubio, P.; Nichols, A.; Mallick, A.; Nawab, A.; Martin, R.; Shah, P.T.; Chaudhry, M.; Sigdel, S.; et al. PNaKtide attenuates steatohepatitis and atherosclerosis by blocking $\mathrm{Na} / \mathrm{K}-\mathrm{ATPase} / \mathrm{ROS}$ amplification in C57B16 and ApoE knockout mice fed a western diet. Sci. Rep. 2017, 7, 193. [CrossRef] [PubMed]

19. Liang, M.; Tian, J.; Liu, L.; Pierre, S.; Liu, J.; Shapiro, J.; Xie, Z.J. Identification of a pool of non-pumping Na/K-ATPase. J. Biol. Chem. 2007, 282, 10585-10593. [CrossRef] [PubMed]

20. Yan, Y.; Haller, S.; Shapiro, A.; Malhotra, N.; Tian, J.; Xie, Z.; Malhotra, D.; Shapiro, J.I.; Liu, J. Ouabain-stimulated trafficking regulation of the Na/K-ATPase and NHE3 in renal proximal tubule cells. Mol. Cell. Biochem. 2012, 367, 175-183. [CrossRef] [PubMed]

21. Liu, J.; Yan, Y.; Liu, L.; Xie, Z.; Malhotra, D.; Joe, B.; Shapiro, J.I. Impairment of Na/K-ATPase signaling in renal proximal tubule contributes to dahl salt-sensitive hypertension. J. Biol. Chem. 2011, 286, 22806-22813. [CrossRef] [PubMed]

22. Yan, Y.; Shapiro, A.P.; Haller, S.; Katragadda, V.; Liu, L.; Tian, J.; Basrur, V.; Malhotra, D.; Xie, Z.J.; Abraham, N.G.; et al. Involvement of reactive oxygen species in a feed-forward mechanism of $\mathrm{Na}$ /K-ATPase-mediated signaling transduction. J. Biol. Chem. 2013, 288, 34249-34258. [CrossRef] [PubMed]

23. Liu, J.; Tian, J.; Haas, M.; Shapiro, J.I.; Askari, A.; Xie, Z. Ouabain interaction with cardiac $\mathrm{Na}^{+} / \mathrm{K}^{+}$-ATPase initiates signal cascades independent of changes in intracellular $\mathrm{Na}^{+}$and $\mathrm{Ca}^{2+}$ concentrations. J. Biol. Chem. 2000, 275, 27838-27844. [PubMed]

24. Xie, Z.; Kometiani, P.; Liu, J.; Li, J.; Shapiro, J.I.; Askari, A. Intracellular reactive oxygen species mediate the linkage of $\mathrm{Na}^{+} / \mathrm{K}^{+}$-ATPase to hypertrophy and its marker genes in cardiac myocytes. J. Biol. Chem. 1999, 274, 19323-19328. [CrossRef] [PubMed]

25. Liu, J.; Kennedy, D.J.; Yan, Y.; Shapiro, J.I. Reactive oxygen species modulation of Na/K-ATPase regulates fibrosis and renal proximal tubular sodium handling. Int. J. Nephrol. 2012, 2012, 381320. [CrossRef] [PubMed]

26. Kennedy, D.J.; Vetteth, S.; Periyasamy, S.M.; Kanj, M.; Fedorova, L.; Khouri, S.; Kahaleh, M.B.; Xie, Z.; Malhotra, D.; Kolodkin, N.I.; et al. Central role for the cardiotonic steroid marinobufagenin in the pathogenesis of experimental uremic cardiomyopathy. Hypertension 2006, 47, 488-495. [CrossRef] [PubMed]

27. Li, Z.; Cai, T.; Tian, J.; Xie, J.X.; Zhao, X.; Liu, L.; Shapiro, J.I.; Xie, Z. Naktide, a Na/K-ATPase-derived peptide src inhibitor, antagonizes ouabain-activated signal transduction in cultured cells. J. Biol. Chem. 2009, 284, 21066-21076. [CrossRef] [PubMed]

28. Tian, J.; Cai, T.; Yuan, Z.; Wang, H.; Liu, L.; Haas, M.; Maksimova, E.; Huang, X.Y.; Xie, Z.J. Binding of $\mathrm{SRC}$ to $\mathrm{Na}^{+} / \mathrm{K}^{+}$-ATPase forms a functional signaling complex. Mol. Biol. Cell 2006, 17, 317-326. [CrossRef] [PubMed]

29. Lopez-Otin, C.; Blasco, M.A.; Partridge, L.; Serrano, M.; Kroemer, G. The hallmarks of aging. Cell 2013, 153, 1194-1217. [CrossRef] [PubMed]

30. Pal, S.; Tyler, J.K. Epigenetics and aging. Sci. Adv. 2016, 2, e1600584. [CrossRef] [PubMed]

31. Chakravarti, B.; Chakravarti, D.N. Oxidative modification of proteins: Age-related changes. Gerontology 2007, 53, 128-139. [CrossRef] [PubMed]

32. Cooke, M.S.; Evans, M.D.; Dizdaroglu, M.; Lunec, J. Oxidative DNA damage: Mechanisms, mutation, and disease. FASEB J. 2003, 17, 1195-1214. [CrossRef] [PubMed]

33. Evans, M.D.; Dizdaroglu, M.; Cooke, M.S. Oxidative DNA damage and disease: Induction, repair and significance. Mutat. Res. 2004, 567, 1-61. [CrossRef] [PubMed]

34. Karihtala, P.; Soini, Y. Reactive oxygen species and antioxidant mechanisms in human tissues and their relation to malignancies. APMIS 2007, 115, 81-103. [CrossRef] [PubMed]

35. Davalli, P.; Mitic, T.; Caporali, A.; Lauriola, A.; D'Arca, D. Ros, cell senescence, and novel molecular mechanisms in aging and age-related diseases. Oxidative Med. Cell. Longev. 2016, 2016, 3565127. [CrossRef] [PubMed]

36. Van Deursen, J.M. The role of senescent cells in ageing. Nature 2014, 509, 439-446. [CrossRef] [PubMed]

37. Passos, J.F.; Nelson, G.; Wang, C.; Richter, T.; Simillion, C.; Proctor, C.J.; Miwa, S.; Olijslagers, S.; Hallinan, J.; Wipat, A.; et al. Feedback between P21 and reactive oxygen production is necessary for cell senescence. Mol. Syst. Biol. 2010, 6, 347. [CrossRef] [PubMed]

38. Wu, J.; Xia, S.; Kalionis, B.; Wan, W.; Sun, T. The role of oxidative stress and inflammation in cardiovascular aging. BioMed Res. Int. 2014, 2014, 615312. [CrossRef] [PubMed] 
39. Harman, D. Aging: A theory based on free radical and radiation chemistry. J. Gerontol. 1956, 11, $298-300$. [CrossRef] [PubMed]

40. Haendeler, J.; Hoffmann, J.; Diehl, J.F.; Vasa, M.; Spyridopoulos, I.; Zeiher, A.M.; Dimmeler, S. Antioxidants inhibit nuclear export of telomerase reverse transcriptase and delay replicative senescence of endothelial cells. Circ. Res. 2004, 94, 768-775. [CrossRef] [PubMed]

41. Aravinthan, A.; Shannon, N.; Heaney, J.; Hoare, M.; Marshall, A.; Alexander, G.J. The senescent hepatocyte gene signature in chronic liver disease. Exp. Gerontol. 2014, 60, 37-45. [CrossRef] [PubMed]

42. Liu, D.; Xu, Y. P53, oxidative stress; and aging. Antioxid. Redox Signal. 2011, 15, 1669-1678. [CrossRef] [PubMed]

43. Gire, V.; Roux, P.; Wynford-Thomas, D.; Brondello, J.M.; Dulic, V. DNA damage checkpoint kinase CHK2 triggers replicative senescence. EMBO J. 2004, 23, 2554-2563. [CrossRef] [PubMed]

44. Campisi, J. Aging, cellular senescence, and cancer. Annu. Rev. Physiol. 2013, 75, 685-705. [CrossRef] [PubMed]

45. Chayapong, J.; Madhyastha, H.; Madhyastha, R.; Nurrahmah, Q.I.; Nakajima, Y.; Choijookhuu, N.; Hishikawa, Y.; Maruyama, M. Arsenic trioxide induces ROS activity and DNA damage, leading to G0/G1 extension in skin fibroblasts through the ATM-ATR-associated chk pathway. Environ. Sci. Pollut. Res. Int. 2017, 24, 5316-5325. [CrossRef] [PubMed]

46. O'Mahony, L.; Holland, J.; Jackson, J.; Feighery, C.; Hennessy, T.P.; Mealy, K. Quantitative intracellular cytokine measurement: Age-related changes in proinflammatory cytokine production. Clin. Exp. Immunol. 1998, 113, 213-219. [CrossRef] [PubMed]

47. Chiricolo, M.; Bartolini, G.; Orlandi, M.; Peta, G.; Corneli, M.; Spinosa, M.; Tomasi, V.; Franceschi, C. Prostaglandin and thromboxane biosynthesis in resting and activated platelet-free monocytes from aged subjects. Gerontology 1986, 32, 69-73. [CrossRef] [PubMed]

48. Franceschi, C.; Bonafe, M.; Valensin, S.; Olivieri, F.; De Luca, M.; Ottaviani, E.; De Benedictis, G. Inflamm-aging. An evolutionary perspective on immunosenescence. Ann. N. Y. Acad. Sci. 2000, 908, 244-254. [CrossRef] [PubMed]

49. Chen, Q.; Ames, B.N. Senescence-like growth arrest induced by hydrogen peroxide in human diploid fibroblast F65 cells. Proc. Natl. Acad. Sci. USA. 1994, 91, 4130-4134. [CrossRef] [PubMed]

50. Hales, C.M.; Carroll, M.D.; Fryar, C.D.; Ogden, C.L. Prevalence of obesity among adults and youth: United states, 2015-2016. NCHS Data Brief 2017, 288, 1-8.

51. Thorpe, R.J., Jr.; Ferraro, K.F. Aging, obesity, and mortality: Misplaced concern about obese older people? Res. Aging 2004, 26, 108-129. [CrossRef] [PubMed]

52. Iyer, A.; Fairlie, D.P.; Prins, J.B.; Hammock, B.D.; Brown, L. Inflammatory lipid mediators in adipocyte function and obesity. Nat. Rev. Endocrinol. 2010, 6, 71-82. [CrossRef] [PubMed]

53. Vidal-Puig, A.; Jimenez-Linan, M.; Lowell, B.B.; Hamann, A.; Hu, E.; Spiegelman, B.; Flier, J.S.; Moller, D.E. Regulation of ppar gamma gene expression by nutrition and obesity in rodents. J. Clin. Investig. 1996, 97, 2553-2561. [CrossRef] [PubMed]

54. Puri, N.; Sodhi, K.; Haarstad, M.; Kim, D.H.; Bohinc, S.; Foglio, E.; Favero, G.; Abraham, N.G. Heme induced oxidative stress attenuates sirtuin 1 and enhances adipogenesis in mesenchymal stem cells and mouse pre-adipocytes. J. Cell. Biochem. 2012, 113, 1926-1935. [CrossRef] [PubMed]

55. Takahashi, M.; Kamei, Y.; Ezaki, O. Mest/Peg1 imprinted gene enlarges adipocytes and is a marker of adipocyte size. Am. J. Physiol. Endocrinol. Metab. 2005, 288, E117-E124. [CrossRef] [PubMed]

56. Monickaraj, F.; Aravind, S.; Nandhini, P.; Prabu, P.; Sathishkumar, C.; Mohan, V.; Balasubramanyam, M. Accelerated fat cell aging links oxidative stress and insulin resistance in adipocytes. J. Biosci. 2013, 38, 113-122. [CrossRef] [PubMed]

57. Marseglia, L.; Manti, S.; D’Angelo, G.; Nicotera, A.; Parisi, E.; Di Rosa, G.; Gitto, E.; Arrigo, T. Oxidative stress in obesity: A critical component in human diseases. Int. J. Mol. Sci. 2014, 16, 378-400. [CrossRef] [PubMed]

58. Findeisen, H.M.; Pearson, K.J.; Gizard, F.; Zhao, Y.; Qing, H.; Jones, K.L.; Cohn, D.; Heywood, E.B.; de Cabo, R.; Bruemmer, D. Oxidative stress accumulates in adipose tissue during aging and inhibits adipogenesis. PLoS ONE 2011, 6, e18532. [CrossRef] [PubMed] 
59. Bailey-Downs, L.C.; Tucsek, Z.; Toth, P.; Sosnowska, D.; Gautam, T.; Sonntag, W.E.; Csiszar, A.; Ungvari, Z. Aging exacerbates obesity-induced oxidative stress and inflammation in perivascular adipose tissue in mice: A paracrine mechanism contributing to vascular redox dysregulation and inflammation. J. Gerontol. Ser. A 2013, 68, 780-792. [CrossRef] [PubMed]

60. Li, M.; Kim, D.H.; Tsenovoy, P.L.; Peterson, S.J.; Rezzani, R.; Rodella, L.F.; Aronow, W.S.; Ikehara, S.; Abraham, N.G. Treatment of obese diabetic mice with a heme oxygenase inducer reduces visceral and subcutaneous adiposity, increases adiponectin levels, and improves insulin sensitivity and glucose tolerance. Diabetes 2008, 57, 1526-1535. [CrossRef] [PubMed]

61. Frasca, D.; Blomberg, B.B.; Paganelli, R. Aging, obesity, and inflammatory age-related diseases. Front. Immunol. 2017, 8, 1745. [CrossRef] [PubMed]

62. Von Zglinicki, T. Oxidative stress shortens telomeres. Trends Biochem. Sci. 2002, 27, 339-344. [CrossRef]

63. Lee, M.; Martin, H.; Firpo, M.A.; Demerath, E.W. Inverse association between adiposity and telomere length: The fels longitudinal study. Am. J. Hum. Biol 2011, 23, 100-106. [CrossRef] [PubMed]

64. Minamino, T.; Orimo, M.; Shimizu, I.; Kunieda, T.; Yokoyama, M.; Ito, T.; Nojima, A.; Nabetani, A.; Oike, Y.; Matsubara, H.; et al. A crucial role for adipose tissue p53 in the regulation of insulin resistance. Nat. Med. 2009, 15, 1082-1087. [CrossRef] [PubMed]

65. Stout, M.B.; Justice, J.N.; Nicklas, B.J.; Kirkland, J.L. Physiological aging: Links among adipose tissue dysfunction, diabetes, and frailty. Physiology 2017, 32, 9-19. [CrossRef] [PubMed]

66. Russell, S.J.; Kahn, C.R. Endocrine regulation of ageing. Nat. Rev. Mol. Cell Biol. 2007, 8, 681-691. [CrossRef] [PubMed]

67. American Heart Association (AHA). Statistical Fact Sheet 2016 Update: Older Americans E Cardiovascular Diseases; AHA: Dallas, TX, USA, 2016.

68. Mohmand, B.; Malhotra, D.K.; Shapiro, J.I. Uremic cardiomyopathy: Role of circulating digitalis like substances. Front. Biosci. 2005, 10, 2036-2044. [CrossRef] [PubMed]

69. Bonomini, F.; Tengattini, S.; Fabiano, A.; Bianchi, R.; Rezzani, R. Atherosclerosis and oxidative stress. Histol. Histopathol. 2008, 23, 381-390. [PubMed]

70. Harrison, D.; Griendling, K.K.; Landmesser, U.; Hornig, B.; Drexler, H. Role of oxidative stress in atherosclerosis. Am. J. Cardiol. 2003, 91,7A-11A. [CrossRef]

71. Vogiatzi, G.; Tousoulis, D.; Stefanadis, C. The role of oxidative stress in atherosclerosis. Hell. J. Cardiol. 2009, 50, 402-409.

72. Boudina, S. Cardiac aging and insulin resistance: Could insulin/insulin-like growth factor (IGF) signaling be used as a therapeutic target? Curr. Pharm. Des. 2013, 19, 5684-5694. [CrossRef] [PubMed]

73. Lakshmi, S.V.; Padmaja, G.; Kuppusamy, P.; Kutala, V.K. Oxidative stress in cardiovascular disease. Indian J. Biochem. Biophys. 2009, 46, 421-440. [PubMed]

74. Sudheesh, N.P.; Ajith, T.A.; Ramnath, V.; Janardhanan, K.K. Therapeutic potential of Ganoderma lucidum (Fr.) P. Karst. against the declined antioxidant status in the mitochondria of post-mitotic tissues of aged mice. Clin. Nutr. 2010, 29, 406-412. [CrossRef] [PubMed]

75. Davalos, A.R.; Coppe, J.P.; Campisi, J.; Desprez, P.Y. Senescent cells as a source of inflammatory factors for tumor progression. Cancer Metastasis Rev. 2010, 29, 273-283. [CrossRef] [PubMed]

76. Freund, A.; Orjalo, A.V.; Desprez, P.Y.; Campisi, J. Inflammatory networks during cellular senescence: Causes and consequences. Trends Mol. Med. 2010, 16, 238-246. [CrossRef] [PubMed]

77. Laberge, R.M.; Sun, Y.; Orjalo, A.V.; Patil, C.K.; Freund, A.; Zhou, L.; Curran, S.C.; Davalos, A.R.; Wilson-Edell, K.A.; Liu, S.; et al. Mtor regulates the pro-tumorigenic senescence-associated secretory phenotype by promoting il1a translation. Nat. Cell Biol. 2015, 17, 1049-1061. [CrossRef] [PubMed]

78. Herranz, N.; Gallage, S.; Mellone, M.; Wuestefeld, T.; Klotz, S.; Hanley, C.J.; Raguz, S.; Acosta, J.C.; Innes, A.J.; Banito, A.; et al. Mtor regulates mapkapk2 translation to control the senescence-associated secretory phenotype. Nat. Cell Biol. 2015, 17, 1205-1217. [CrossRef] [PubMed]

79. Wajapeyee, N.; Serra, R.W.; Zhu, X.; Mahalingam, M.; Green, M.R. Oncogenic braf induces senescence and apoptosis through pathways mediated by the secreted protein IGFBP7. Cell 2008, 132, 363-374. [CrossRef] [PubMed]

80. Hubackova, S.; Krejcikova, K.; Bartek, J.; Hodny, Z. IL1- and TGFbeta-nox4 signaling, oxidative stress and DNA damage response are shared features of replicative; oncogene-induced; and drug-induced paracrine 'bystander senescence'. Aging 2012, 4, 932-951. [CrossRef] [PubMed] 
81. McNeal, A.S.; Liu, K.; Nakhate, V.; Natale, C.A.; Duperret, E.K.; Capell, B.C.; Dentchev, T.; Berger, S.L.; Herlyn, M.; Seykora, J.T.; et al. Cdkn2b loss promotes progression from benign melanocytic nevus to melanoma. Cancer Discov. 2015, 5, 1072-1085. [CrossRef] [PubMed]

82. Soto-Gamez, A.; Demaria, M. Therapeutic interventions for aging: The case of cellular senescence. Drug Discov. Today 2017, 22, 786-795. [CrossRef] [PubMed]

83. Schlossmacher, G.; Stevens, A.; White, A. Glucocorticoid receptor-mediated apoptosis: Mechanisms of resistance in cancer cells. J. Endocrinol. 2011, 211, 17-25. [CrossRef] [PubMed]

84. Zhu, Y.; Tchkonia, T.; Pirtskhalava, T.; Gower, A.C.; Ding, H.; Giorgadze, N.; Palmer, A.K.; Ikeno, Y.; Hubbard, G.B.; Lenburg, M.; et al. The achilles' heel of senescent cells: From transcriptome to senolytic drugs. Aging Cell 2015, 14, 644-658. [CrossRef] [PubMed]

85. Zhu, Y.; Tchkonia, T.; Fuhrmann-Stroissnigg, H.; Dai, H.M.; Ling, Y.Y.; Stout, M.B.; Pirtskhalava, T.; Giorgadze, N.; Johnson, K.O.; Giles, C.B.; et al. Identification of a novel senolytic agent, navitoclax, targeting the BCL-2 family of anti-apoptotic factors. Aging Cell 2016, 15, 428-435. [CrossRef] [PubMed]

(C) 2018 by the authors. Licensee MDPI, Basel, Switzerland. This article is an open access article distributed under the terms and conditions of the Creative Commons Attribution (CC BY) license (http:/ / creativecommons.org/licenses/by/4.0/). 